\section{Influence of Pumice and Plant Roots on Substrate Physical Properties Over Time}

\author{
James E. Altland ${ }^{1,4}$, James S. Owen, Jr. ${ }^{2}$, and Magdalena Z. Gabriel ${ }^{3}$
}

ADDITIONAL INDEX WORDS. media, container capacity, air space, total porosity, water holding capacity, water management.

Summary. An experiment was conducted to test the hypothesis that either pumice or plant roots maintain air space (AS) and porosity over time, or renders substrates more resistant to shrinkage. Treatment design was a $3 \times 2$ factorial with three substrate types and either presence or absence of a plant. The three substrates were composed of douglas fir (Pseudotsuga menziesii) bark alone or amended with $15 \%$ or $30 \%$ (by volume) pumice. Substrates were packed in aluminum cores to facilitate measurement of physical properties with porometers at the conclusion of the experiment. Half of the cores with each of the three substrate types were packed with a single plug of 'Autumn Blush' coreopsis (Coreopsis sp.) (Expt. 1) or 'Blue Prince' holly (Ilex $\times$ meserveae) (Expt. 2). The remaining cores were maintained in the same production environment, but without a plant. Substrate physical properties were measured before the experiment and after 48 days for coreopsis plants and 382 days for holly. Both experiments had relatively similar responses despite using different crops and production times. Summarizing in general overall treatments, AS decreased, container capacity (CC) and total porosity (TP) increased, and bulk density remained constant over time. The presence of a plant in the core tended to exacerbate the decrease in AS and the increase in core capacity. Shrinkage was decreased by the presence of a plant, but only minimally.

S oilless substrates are dynamic due to their predominantly organic nature, changing both physically and chemically over time. Substrate decomposition, settling, or a combination of the two can cause shrinkage in substrates. This shrinkage or reduction in substrate volume results in a change in physical properties that affect AS and CC. Aendekerk (1997) showed the relative decomposition and shrinkage of several peat sources as a function of substrate $\mathrm{pH}$ and sub-irrigation level. While $\mathrm{pH}$ and sub-irrigation level both influenced $\mathrm{AS}, \mathrm{pH}$ as a function of peat source was more influential than irrigation factors. Allaire-Leung et al. (1999) showed that AS in peat substrates decreased and easily available water increased over a 14-month period, with a net effect of no change

Mention of proprietary products or company is included for the reader's convenience and does not imply any endorsement or preferential treatment by USDA-ARS

${ }^{1}$ Research Horticulturist, USDA-ARS, Application Technology Research Unit, OH Agricultural Research and Development Center, 1680 Madison Avenue, Wooster, OH 44691

${ }^{2}$ Assistant Professor, Oregon State University, North Willamette Research and Extension Center, 15210 NE Miley Road, Aurora, OR 97002-9543

${ }^{3}$ Graduate student, Oregon State University, North Willamette Research and Extension Center, 15210 NE Miley Road, Aurora, OR 97002-9543

${ }^{4}$ Corresponding author. E-mail: James.Altland@ars. usda.gov. in TP. Settling and decomposition of peat-based substrates may be more common than in bark-based substrates. Nash and Laiche (1981) reported that increasing levels of peat relative to bark in substrates caused an increase in the amount of shrinkage. However, they also reported that a 4 bark: 1 sand substrate had decreased hydraulic conductivity after 5 months, whereas several substrates with varying bark:peat ratios had increased hydraulic conductivity.

Nursery and greenhouse growers attempt to overcome substrate shrinkage by adding components that are not subject to change due to their inert, stable, inorganic composition. Nursery growers in the Pacific northwestern United States use pumice as the primary inorganic substrate component. Pumice is a porous igneous rock found primarily in volcanic regions of the world, including the Cascade Mountain Range in Oregon. The impact of pumice on crop growth and substrate physical properties has been studied throughout the world, as pumice from each volcanic region has unique properties (Gizas and Savvas, 2007; Gunnlaugsson and Adalsteinsson, 1995; Lenzi et al., 2001). Pumice is usually added to nursery substrates at rates of $10 \%$ to $20 \%(\mathrm{v} / \mathrm{v})$ because it is perceived to increase aeration and drainage. Recent research contradicts these perceptions by showing additions of pumice to douglas fir bark (DFB) decreased TP, CC, available water, and water buffering capacity (water occurring between 5.0 and $9.9 \mathrm{kPa})$, but increased bulk density $\left(D_{\mathrm{b}}\right)$ (Gabriel et al., 2009). In addition, it was hypothesized by growers that including a stable inorganic substrate component that cannot decompose would maintain structure in organic substrates and create more uniform physical properties throughout the growing season. It has also been speculated that plant roots form an effective scaffolding that maintains substrate structure and thus limit change to the physical properties of the substrate. Aendekerk (1997) supported this hypothesis by showing an average of $8 \%$ shrinkage after 31 weeks across four different peat substrates potted with 'Rubinetta' skimmia (Skimmia japonica), but over $18 \%$ shrinkage during the same time in containers without a plant. The objective of this research was to test the hypothesis that pumice maintains AS and porosity over time or renders substrates more resistant to shrinkage. A second objective of this research is to test the alternative hypothesis that plant roots alone maintain substrate structure thus preventing shrinkage.

\section{Materials and methods}

A $7.5 \times 7.5$-inch square of 20 mesh fiberglass insect screen (Phifer Wire Products, Tuscaloosa, AL) was used to cover the bottom of aluminum cylinders (sampling cores) 6-inch tall

\begin{tabular}{llll}
\hline $\begin{array}{l}\text { Units } \\
\begin{array}{l}\text { To convert U.S. to SI, } \\
\text { multiply by }\end{array}\end{array}$ & U.S. unit & SI unit & $\begin{array}{l}\text { To convert SI to U.S., } \\
\text { multiply by }\end{array}$ \\
\hline 2.54 & inch $(\mathrm{es})$ & $\mathrm{cm}$ & 0.3937 \\
25.4 & inch $(\mathrm{es})$ & $\mathrm{mm}$ & 0.0394 \\
1.7300 & $\mathrm{Oz} / \mathrm{inch}^{3}$ & $\mathrm{~g} \cdot \mathrm{cm}^{-3}$ & 0.5780 \\
1 & $\mathrm{Ppm}$ & $\mathrm{mg} \cdot \mathrm{L}^{-1}$ & 1 \\
6.8948 & $\mathrm{Psi}$ & $\mathrm{kPa}$ & 0.1450 \\
$\left({ }^{\circ} \mathrm{F}-32\right) \div 1.8$ & ${ }^{\circ} \mathrm{F}$ & ${ }^{\circ} \mathrm{C}$ & $\left(1.8 \times{ }^{\circ} \mathrm{C}\right)+32$ \\
$\left({ }^{\circ} \mathrm{F} \div 1.8\right)+255.37$ & ${ }^{\circ} \mathrm{F}$ & $\mathrm{K}$ & $(\mathrm{K}-255.37) \times 1.8$
\end{tabular}


with 3 -inch i.d. using a 0.5 -inch-wide rubber band (size 84). Aluminum cores were extended temporarily for the packing procedure by adding an additional 1.5-inch-tall $\times 3$-inch i.d. core on top of the planting core. Cores were packed with each soilless substrate by dropping the core from a height of 2.5 inches five times to imitate common industry packing procedures. The core extension was then removed such that the substrate surface within the core was level with the top of the core. Treatment design was a $3 \times 2$ factorial with three substrate types and either presence or absence of a plant. The three substrates were composed of DFB alone or amended with $15 \%$ or $30 \%$ (by volume) pumice. In Expt. 1, cores that were randomly assigned to receive a plant were packed with a single plug of coreopsis from a 288-cell pack. Plugs were rinsed free of media and pruned to have an approximate root and shoot length of 3 and $4.5 \mathrm{~cm}$, respectively, and gravity planted as the column was packed to ensure substrate was unaffected. There were six replications per treatment combination arranged in a completely randomized design. The experiment was conducted in a polyethylene-covered hoop house in Aurora, OR.

The first $3 \mathrm{~d}$ following potting, cores were overhead irrigated $(5 \mathrm{H}$ Series MPR nozzles; Rain Bird Corp., Azusa, CA) in three sets of $7 \mathrm{~min}\left(\approx 1.1 \mathrm{~cm} \cdot \mathrm{d}^{-1}\right)$. Thereafter, cores were fertigated at the same irrigation rate with $20 \mathrm{~N}-8.7 \mathrm{P}-$ $16.6 \mathrm{~K}-0.05 \mathrm{Mg}$ fertilizer containing a chelating formula with micronutrients $(0.0068 \mathrm{~B}-0.0036 \mathrm{Cu}-0.05 \mathrm{Fe}-$ $0.025 \mathrm{Mn}-0.0009 \mathrm{Mo}-0.0025 \mathrm{Zn}$ ) (Peters Professional M-77; Scotts, Marysville, $\mathrm{OH}$ ). Fertilizer was injected at a constant feed nitrogen rate of $150 \mathrm{mg} \cdot \mathrm{L}^{-1}$ with an injector (DIl6; Dosatron International, Clearwater, FL) with a calibrated injection rate of $1: 100$.

The experiment was initiated on 22 Sept. 2007 and ended on 9 Nov. 2007. At the conclusion of the experiment, aluminum cores were attached to porometers for determination of physical properties using methods described by Fonteno and Bilderback (1993). Briefly, cores were saturated and drained to determine AS. Cores were oven dried for $4 \mathrm{~d}$ at $60{ }^{\circ} \mathrm{C}$ to determine CC. Total porosity was calculated as the sum of AS and CC.
Bulk density was calculated as grams per cubic centimeter on a dry basis. Shrinkage was determined by measuring the distance between the top of the core and the substrate surface. The shrinkage value was determined by the mean of four measurements around the circumference of the core. Two additional cores of each substrate combination were packed (without plants) using the same procedures described above so that physical properties could be determined at the initiation of the experiment.

The experiment was repeated using the same procedures described above, with the following exceptions. In Expt. 2, 'Blue Prince' holly were potted into the aluminum cores on 8 Mar. 2007 and grown until 25 Mar. 2008. All cores were located in a retractable-roof greenhouse in which the roof remained open throughout the spring and summer months, but closed throughout the winter months. Cores were irrigated and fertilized with the same equipment and rates as those described for Expt. 1.

Data were analyzed with analysis of variance to determine influence of main effects on individual parameters. Means separation using Fisher's protected least significant difference test was used to compare means of initial physical properties. Regression analysis was performed using orthogonal contrast statements to detect linear or quadratic responses of each measured parameter to pumice rate.

\section{Results and discussion}

Expт. 1. Coreopsis was grown for $48 \mathrm{~d}$, at which time they were subject to an errant herbicide application which damaged the foliage. The experiment was ended on the same day to avoid potentially confounding effects from the herbicide. Coreopsis was well established, but not fully grown at the time of harvest.

The addition of pumice to the substrate decreased AS at the initiation of the experiment (Table 1). By the end of the experiment, the plant presence and pumice level interacted to affect AS (Table 2). Pumice level did not affect AS in the absence of a plant, but we observed a linear increase in AS with increasing pumice level in the presence of a plant. Change in AS $(\triangle \mathrm{AS})$ was similarly affected by an interaction of plant presence and pumice level. Change was more dramatic for cores with plants than those without. Without plants, AS responded quadratically to increasing pumice level; with plants AS decreased linearly with increasing pumice level. Others have reported decrease in AS over time with peat-based substrates in the presence of a plant (Aendekerk, 1997; AllaireLeung et al., 1999; Nelson et al., 2004). Initially, pumice level had no effect on substrate CC (Table 1). After $48 \mathrm{~d}$, only the presence of coreopsis affected CC, with slightly higher CC in cores with coreopsis ( $48 \%$ vs. $46 \%$, Table 2). Both plant presence and pumice level affected $\Delta C \mathrm{C}$. Either with or without a plant, $\Delta \mathrm{CC}$ responded quadratically to pumice level with $15 \%$ pumice causing a smaller increase of $\Delta \mathrm{CC}$ than $0 \%$ or $30 \%$ pumice.

Total porosity was not measured directly, but determined by summing values for AS and CC. At the beginning of the experiment, adding 15\% or $30 \%$ pumice decreased TP slightly compared with cores without pumice (Table 1). Pumice level did not affect TP by the conclusion of the study in the presence of a plant (Table 2). Cores with a plant had slightly lower TP $(78 \%)$ than those without plants (81\%). Both plant presence and pumice level, but not their interaction, affected $\Delta \mathrm{TP}$. Averaging across pumice levels, cores with plants had a smaller increase in $\triangle \mathrm{TP}$ than those without. Averaging across plant effect, cores without pumice had lower $\Delta \mathrm{TP}$, whereas those with $15 \%$ or $30 \%$ pumice had greater $\Delta \mathrm{TP}$.

Substrate $D_{\mathrm{b}}$ was affected by pumice level only. There was virtually no change in $D_{\mathrm{b}}$ over time (Table 2 ). Data analysis shows that pumice level influenced change in $D_{\mathrm{b}}(P=0.02)$; however, mean change for each treatment was less than the number of significant units used for measuring density $\left(0.01 \mathrm{~g} \cdot \mathrm{cm}^{-3}\right)$. The presence of a plant in the cores affected shrinkage. However, with a difference of just $0.1 \mathrm{~mm}$ shrinkage between those with and without plants, differences were less than $0.1 \%$ of core height, and thus inconsequential.

EXPт. 2. Holly was maintained in cores for over 1 year $(382 \mathrm{~d})$. This duration would be more representative of the production cycle for outdoor nursery crops. The presence of holly and pumice level, but not their interaction, affected AS (Table 3). Similar to the previous experiment, 
cores without a plant responded quadratically to pumice level with $0 \%$ or $30 \%$ pumice losing more AS than $15 \%$ pumice. Similar to the previous study, cores with holly lost more AS than those without. The presence of holly, but not pumice level or their interaction, affected $\mathrm{CC}$ and $\triangle \mathrm{CC}$. Cores with plants had greater $\mathrm{CC}$ and $\triangle \mathrm{CC}$ than those without. Total porosity increased for all treatments. Cores with plants had greater increase in TP than those without. Similar to the previous study, $D_{\mathrm{b}}$ changed little over time. Although statistical analysis shows significant changes in $D_{\mathrm{b}}$ caused by plant presence and pumice level, changes were minor across all treatments. Shrinkage in cores without plants was greater than those with plants. This concurs with research by Aendekerk (1997) in which containers with skimmia had less shrinkage than those with no plant. Despite significant differences among treatments in our experiment, overall shrinkage was minor. Cores used in this study were $152-\mathrm{mm}$ tall, thus shrinkage of $1 \mathrm{~mm}$ accounts for less than $1 \%$ of total core height.

In summary, both experiments had relatively similar responses despite using different crops and production times. Summarizing overall treatments, AS decreased, CC and TP increased, and $D_{\mathrm{b}}$ changed very little over time. The presence of a plant in the core tended to exacerbate the decrease in AS and the increase in CC. Shrinkage was affected by the presence of a plant, but only minimally.

Air space in this study was measured by recording the volume of water draining from each core after complete saturation. It reasons that this volume represents the fraction of void spaces (pore spaces not occupied by roots)

Table 1. Initial physical properties of three douglas fir bark (DFB) and pumice (P) substrates.

\begin{tabular}{llllc}
\hline & \multicolumn{4}{c}{ Physical properties $^{\mathrm{z}}$} \\
\cline { 2 - 5 } Substrate (DFB:P) & TP & AS & CC & \\
\cline { 2 - 4 } $100: 0$ & $79 \mathrm{a}^{\mathrm{x}}$ & $41 \mathrm{a}$ & $38 \mathrm{a}$ & $0.18 \mathrm{c}$ \\
$85: 15$ & $75 \mathrm{~b}$ & $35 \mathrm{~b}$ & $40 \mathrm{a}$ & $0.21 \mathrm{~b}$ \\
$70: 30$ & $76 \mathrm{~b}$ & $37 \mathrm{~b}$ & $39 \mathrm{a}$ & $0.25 \mathrm{a}$ \\
\hline
\end{tabular}

${ }^{2} \mathrm{TP}=$ total porosity, $\mathrm{AS}=$ air space, $\mathrm{CC}=$ container capacity, $D_{\mathrm{b}}=$ bulk density.

$\mathrm{y} / \mathrm{g} \cdot \mathrm{cm}^{-3}=0.5780 \mathrm{oz} /$ inch $^{3}$.

${ }^{x}$ Means with different letters are significantly different according to Fisher's protected least significant difference test at $\alpha=0.05$

Table 2. Physical properties of douglas fir bark (DFB) and pumice (P) substrates after exposure to production environment with or without 'Sunray' coreopsis growing within the core.

\begin{tabular}{|c|c|c|c|c|c|c|c|c|c|c|}
\hline \multirow[b]{3}{*}{ Plant } & \multirow[b]{3}{*}{ Substrate (DFB:P) } & \multicolumn{8}{|c|}{ Physical properties ${ }^{z}$} & \multirow[b]{3}{*}{ Shrinkage $(\mathrm{mm})$} \\
\hline & & $\overline{\mathrm{AS}}$ & $\Delta \mathrm{AS}$ & $\mathrm{CC}$ & $\Delta \mathrm{CC}$ & TP & $\Delta \mathrm{TP}$ & $D_{\mathrm{b}}$ & $\overline{\Delta D_{\mathrm{b}}}$ & \\
\hline & & \multicolumn{6}{|c|}{$(\%)$} & \multicolumn{2}{|c|}{$\left(\mathrm{g} \cdot \mathrm{cm}^{-3}\right)^{\mathrm{y}}$} & \\
\hline & $85: 15$ & 36 & 1 & 46 & 6 & 82 & 7 & 0.21 & 0.00 & 0.1 \\
\hline & $70: 30$ & 33 & -4 & 48 & 9 & 81 & 5 & 0.26 & 0.01 & 0.1 \\
\hline \multirow[t]{4}{*}{ Yes } & 100:0 & 26 & -15 & 48 & 10 & 74 & -5 & 0.18 & 0.00 & 0.2 \\
\hline & $85: 15$ & 30 & -5 & 48 & 8 & 78 & 3 & 0.21 & 0.00 & 0.2 \\
\hline & $70: 30$ & 34 & -3 & 49 & 10 & 82 & 6 & 0.25 & 0.00 & 0.2 \\
\hline & & $\mathrm{L}^{*}$ & $\mathrm{~L}^{* * *}$ & NS & $\mathrm{Q}^{*}$ & $\mathrm{~L}^{*}$ & $\mathrm{~L}^{* *}$ & $\mathrm{~L}^{* * *}$ & NS & NS \\
\hline
\end{tabular}

${ }^{2} \mathrm{AS}=$ air space, $\mathrm{CC}=$ container capacity, $\mathrm{TP}=$ total porosity, $D_{\mathrm{b}}=$ bulk density. The symbol $\Delta$ refers to change in the respective parameter from the initial measurement made at the beginning of the study until $48 \mathrm{~d}$ later when the experiment was harvested. NS, L, and Q represent no significant rate response, linear, and quadratic rate response with respect to pumice rate, respectively; ${ }^{*},{ }^{*},{ }^{* * *}$ represent significant effects when $P \leq 0.05,0.01$, and 0.001 , respectively.

${ }^{\mathrm{y}} \mathrm{l} \mathrm{g} \cdot \mathrm{cm}^{-3}=0.5780 \mathrm{oz} / \mathrm{inch}^{3}, 1 \mathrm{~mm}=0.0394$ inch. 
Table 3. Physical properties of douglas fir bark (DFB) and pumice (P) substrates after exposure to production environment with or without 'Blue Prince' holly growing within the core.

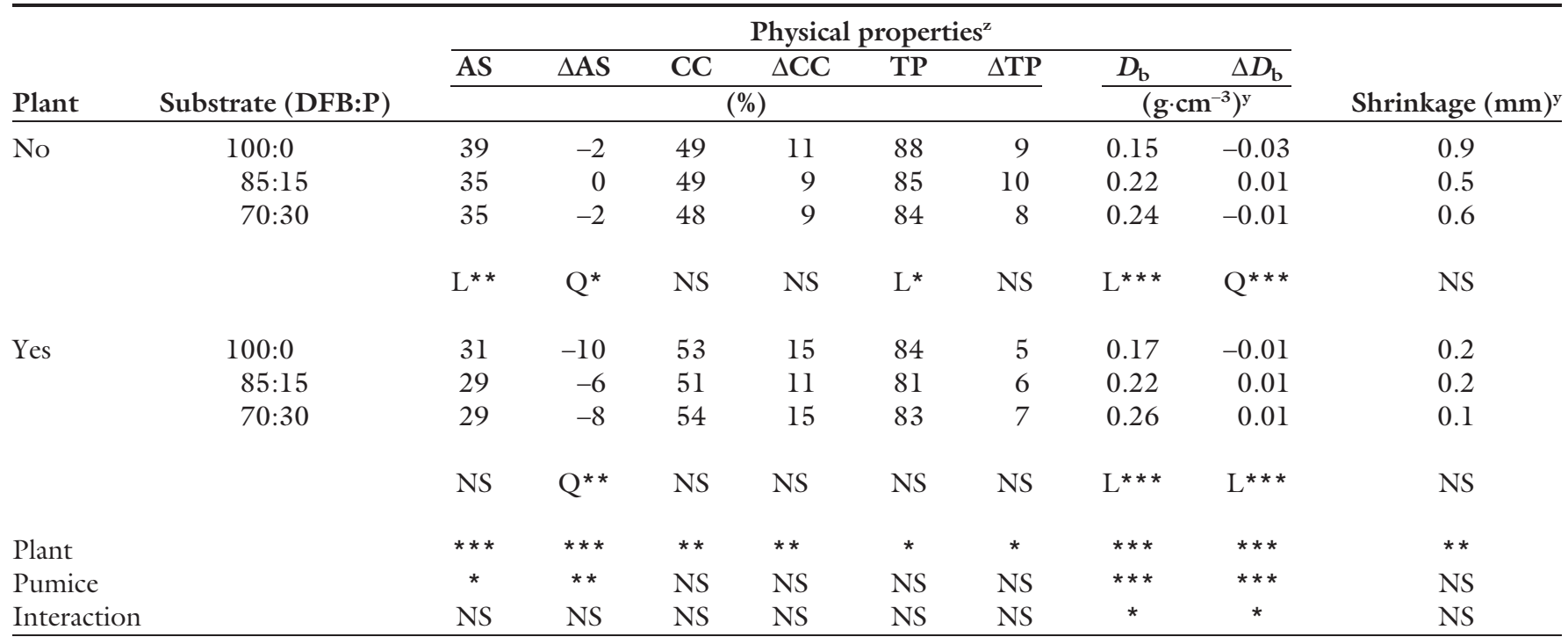

${ }^{\mathrm{z}} \mathrm{AS}=$ air space, $\mathrm{CC}=$ container capacity, $\mathrm{TP}=$ total porosity, $D_{\mathrm{b}}=$ bulk density. The symbol $\Delta$ refers to change in the respective parameter from the initial measurement made at the beginning of the study until $382 \mathrm{~d}$ later when the experiment was harvested. NS, L, and Q represent no significant rate response, linear, and quadratic rate response with respect to pumice rate, respectively; ${ }^{*},{ }^{*},{ }^{* * *}$ represent significant effects when $P \leq 0.05,0.01$, and 0.001 , respectively.

y $1 \mathrm{~g} \cdot \mathrm{cm}^{-3}=0.5780 \mathrm{oz} /$ inch $^{3}, 1 \mathrm{~mm}=0.0394$ inch.

those cores with plants. Increases in $\mathrm{CC}$, regardless of the absence or presence of plants, is likely due to the aforementioned decomposition of organic matter and related changes in pore size.

Changes in $D_{\mathrm{b}}$ were inconsequential. Because herbaceous plant roots are primarily comprised of water, and because $D_{\mathrm{b}}$ measurements are made on oven-dried substrates, it makes sense that plant tissue present in the substrate would have very little effect on $D_{\mathrm{b}}$ measurements. Shrinkage in nursery and greenhouse substrates is most likely related to peat content. Our data show very little shrinkage in bark and pumice substrates. Nash and Laiche (1981) reported 10\% shrinkage of a 4 pine bark: 1 sand substrate $(\mathrm{v} / \mathrm{v})$ compared with $33 \%$ shrinkage of a 1 pine bark:1 peat moss substrate. In their study, shrinkage increased as the percent of peat moss in the substrate increased. Likewise, Nelson et al. (2004) showed that shrinkage in peatbased substrates was incrementally reduced as coir incrementally replaced peat in the substrate.

One of the objectives of this study was to test the hypothesis that pumice maintains AS over time or renders substrates more resistant to shrinkage. In the presence of a plant, the change in AS decreased with increasing pumice rate. Thus, there seems to be validity to this hypothesis. Shrinkage was minimal across all treatments. Considering the literature on shrinkage in peat-based substrates that was summarized above, in conjunction with the results of this research, it is reasonable to assume that shrinkage in nursery substrates is the result of changes in peat moss and not bark or pumice. Either way, the notion that pumice prevents shrinkage in predominantly bark substrates might only be valid if peat moss (or other readily decomposable organic material) is a significant component in the substrate. A second objective of this research was to test the alternative hypothesis that plant roots maintain substrate structure thus maintaining AS and preventing shrinkage. With plants present, AS decreased over time in all substrates in both experiments. Our data and other literature reviewed herein show clearly that AS will decrease as roots fill void spaces. In substrates composed of only bark and pumice, shrinkage was minimal, thus the hypothesis that roots support substrate structure and prevent shrinkage could not be adequately tested.

\section{Literature cited}

Aendekerk, T.G. 1997. Decomposition of peat substrates in relation to physical properties and growth of Chamaecyparis. Acta Hort. 450:191-198.
Allaire-Leung, S.E., J. Caron, and L.E. Parent. 1999. Changes in physical properties of peat substrates during plant growth. Can. J. Soil Sci. 79:137-139.

Fonteno, W.C. and T.E. Bilderback. 1993. Impact of hydrogel on physical properties of coarse-structured horticultural substrates. J. Amer. Soc. Hort. Sci. 118:217-222.

Gabriel, M.Z., J. Altland, and J. Owen, Jr. 2009. Effect of peat moss and pumice on douglas fir bark based soilless substrate physical and hydraulic properties. HortScience 44:874-878.

Gizas, G. and D. Savvas. 2007. Particle size and hydraulic properties of pumice affect growth and yield of greenhouse crops in soilless culture. HortScience 42:1280

Gunnlaugsson, B. and S. Adalsteinsson. 1995. Pumice as environment-friendly substrate-A comparison with rockwool. Acta Hort. 401:131-136.

Lenzi, A., N. Oggiano, M. Maletta, A. Bolaffi, and R. Tesi. 2001. Physical and chemical characteristics of substrates made of perlite, pumice and peat. Italus Hortus 8:23-31.

Nash, V.E. and A.J. Laiche, Jr. 1981. Changes in the characteristics of potting media with time. Commun. Soil Sci. Plant Anal. 12:1011-1020.

Nelson, P.V., Y.M. Oh, and D.K. Cassel. 2004. Changes in physical properties of coir dust substrates during crop production. Acta Hort. 644:261-268. 